\title{
Kajian Penanganan Dampak Banjir Kabupaten Pekalongan
}

\author{
M. Afif Salim ${ }^{1}$, Agus B Siswanto ${ }^{2}$ \\ Dosen Fakultas Teknik Prodi Teknik Sipil, Universitas 17 Agustus 1945 Semarang ${ }^{1,2}$ \\ Email: afifsalim@untagsmg.ac.id ${ }^{1}$, agus_bambang_iswanto@untagsmg.ac.id ${ }^{2}$ \\ DOI: http://dx.doi.org/10.31869/rtj.v4i2.2525
}

\begin{abstract}
Abstrak: Bencana banjir yang terjadi di kabupaten Pekalongan pada Februari 2021 disebabkan oleh tingginya intensitas hujan selama satu minggu dengan curah hujan $>50 \mathrm{~mm} / \mathrm{hari}$ dan pasang surut air laut akibat rob yang mencapai 0,9-1,1 meter.permasalahan lain akibat banjir kabupaten Pekalonganadalah perubahan tata guna lahan, penurunan tanah (land subsidence), sampah, erosisedimentasi, serta faktor operasi dan pemeliharaan. Kerugian akibat bencana banjir menyebabkan kerugian material, bangunan hingga lumpuhnya kondisi lalulintas. Metode yang digunakan dalam penelitian ini adalah dengan pengumpulan data primer dan sekunder, pengolahan data dengan deskriptif kualitatif dengan menggambarkan pemahaman, pendekatan studi/ penelitian dengan observasi dilapangan. Penanganan banjir yang sudah dilakukan adalah dengan menambah pintu sorong darurat pada drainase, pengadaan pompa air mobile kapasitas 250 liter/detik, tanggul CCSP (Corugated Concrete Sheet Pile), rehabilitasi pintu air Sungai Bremi, pembangunan rumah pompa Mrican kapasitas $8 \times 2 \mathrm{~m} 3 /$ detik, dan pembangunan tanggul tanah Silempeng sepanjang 2.200 meter. Adapun penanganan darurat yang dilakukan ketika banjir Februari 2021 adalah dengan pembukaan Long Storage Silempeng- Sengkarang dan penyiapan sandbag serta karung-karung besar untuk penanganan darurat.
\end{abstract}

Keywords: Banjir, Pekalongan, , Penanganan,Rob

\section{PENDAHULUAN}

Pemanasan global yang terjadi memberikan dampak yang mendunia, termasuk Indonesia, salah satu dampaknya adalah kenaikan muka air laut sebagai salah satu akibat mencairnya es di kutub bumi. Kenaikan muka air laut menyebabkan beberapa kerugian seperti abrasi dan banjir pasang air laut atau rob. Banjir dan rob merupakan bencana rutin yang senantiasa terjadi di Kabupaten Pekalongan. Kabupaten Pekalongan merupakan kabupaten yang berada pada pantai utara Jawa dengan ketinggian 0-8 meter diatas permukaan laut.

Luas wilayah Kabupaten Pekalongan adalah $\pm 836,15 \mathrm{Km} 2$. Terdiri atas 19 Kecamatan dan 285 desa/kelurahan. Dari 285 desa/ kelurahan yang ada, 11 desa merupakan desa pantai dan 274 desa bukan desa pantai. Menurut topografi desa, terdapat 66 desa/ kelurahan $(23,16$ persen $)$ yang berada di dataran tinggi dan selebihnya 219 desa/kelurahan (76,84 persen) berada di dataran rendah dan beberapa daerah terdapat di wilayah pesisir. Wilayah pesisir utara pulau Jawa terutama kabupaten yang berada pada area pesisir utara Provinsi jawa Tengah, seperti kabupaten Pekalongan merupakan kabupaten yang sering terkena dampak banjir dan rob (Maulana, 2012).

Bencana merupakan sebuah keadaan ketika lingkungan dapat menimbulkan kerusakan atau kerugian daerah sekitarnya dan kejadian yang terjadi dapat berlangsung secara tiba-tiba maupun perlahan.

Banjir rob perlu ditangani secara terstruktur dan terintegritas dari berbagai pihak yang terkait, agar diperoleh hasil yang maksimal Secara lingkungan peran dan kontribusi pihak terkait harus mengetahui, memahami dan mengerti secara detail sehingga permasalahan dapat diselesaikan secara konkrit ( Kodoatie, 2013).

Bencana juga digolongkan jika terdapat lingkungan manusia yang terkena dampak tersebut. Dampaknya sendiri dapat secara langsung yang berupa kerusakan pada sektor primer dan dampak tidak langsung berupa kerusakan sektor-sektor pendukung kegiatan dan aktivitas manusia, seperti karingan transportas-komunikasi, infrastruktur, dan pendukung lainnya, (Hermawan, 2011).

Penyebab bencana banjir tidak hanya disebabkan oleh kenaikan tinggi muka air laut yang menambah buruknya dampak banjir rob, namun faktor lainnya yang ikut berpenaruh seperti karakteristik dari geomorfologi pesisir 
yang terdiri dari dataran lumpur dan pantai berpasir yang memiliki elevasi kurang dari 5 meter.

Beberapa dampak yang ditimbulkan karena adanya banjir Rob antara lain :

1. Menimbulkan kerugian material

Dampak yang sudah pasti dirasakan bagi masyarakat yang mengalami banjir Rob adalah berupa kerugian material. Kerugian material ini merupakan dapat timbul karena banyak rumah warga yang terendam banjir, kemudian tidak hanya rumah saja namun juga perabotan rumah tangga ikut terendam banjir. Hal ini akan mengakibatkan adanya kergian material yang cukup besar untuk dapat memulihkan seperti kondisi semula.

\section{Merusak bangunan}

Dampak yang juga sangat dirasakan oleh masyarakat akibat banjir Rob adalah rusaknya bangunan yang terendam banjir. Bangunan yang terlalu lama tergenang air memang akan mengalami kerusakan, baik banyak maupun sedikit. serapan bangunan yang berpotensi rusak adalah lantai atau keramik, kusen pintu, maupun tembok bagian bawah.

3. Menyebabkan lingkungan menjadi kotor dan becek

Dampak yang pasti terjadi ketik banjir datang adalah lingkungan menjadi kotor dan becek. Hal ini karena air yang meluap tidak hanya melintas namun juga menggenangi. Akibatnya, hal ini akan membuat lingkungan yang digeangi air menjadi becek dan tidak nyaman, sehingga akan menjadi kotor.

4. Menyebarnya bibit penyakit

Banjir secara tidak langsung baik cepet maupun lambat akan menyebarkan bibit penyakit. Hal ini seperti sudah menjadi paket dan kita semua pun mengerti bahwa banjir akan menjadi penyebab timbulnya berbagai jenis penyakit. Beberapa penyakit yang dapat ditimbulkan dari banjir Rob ini antara lain adalah diare, ISPA, gatal- gatal, hingga demam berdarah. Maka dari itulah ketika banjir datang menyerang akan banyak orangorang yang terkena penyakit.

\section{Mengganggu lalu lintas}

Dampak negatif dari banjir yang selanjutnya adalah mengganggu kelancaran lalu lintas. Hal ini karena air yang menggenangi akibat banjir tidak hanya menggenangi pemukiman penduduk seperti perumahan, namun juga jalan raya. Sehingga hal ini akan menyebabkan terganggunya lalu lintas di jalan yang tergenang air tersebut. Tidak hanya mengganggu lalu lintas saja, namun banjir Rob juga dapat membuat mesinmesin kendaraan menjadi mati atau bahkan rusak.

6. Kelangkaan air bersih

Satu hal yang selalu muncul ketika banjir tiba adalah kelankaan air bersih. Bagaimanapun juga air banjir tidak hanya menggenangi rumah masyarakat saja, namun juga sumber air bersih bagi masyarakat. Akibatnya air bersih yang seharusnya digunakan untuk konsumsi warga sehari- hari dapat bercampur dengan air banjir. Belum lagi septiktank warga yang juga terendam air banjir dapat berpotensi membuat tinja menjadi keluar dan bercampur dengan air warga. Hal ini sungguh menimbulkan krisis air bersih.

Bencana banjir mengurangi tingkat kualitas hidup dan kesejahteraan masyarakat.

Dampak negatif bencana banir akibat rob khusunya kepada sektor perekonomian dapat menimbulkan kerugian bagi wilayah di pesisir yang terpapar banjir rob. Gangguan ini berdampak secara langsung dengan mengakibatkan berkurangnya intensivitas dan bahkan mengakibatkan kelumpuhan aktivitas kegiatan perekonomian wilayah pesisir saat terjadi banjir. Potensi pada bidang pertanian dan potensi lainnya tentu memerlukan pengelolaan yang tepat guna agar bermanfaat dan berkelanjutan, mengingat wilayah pesisir Indonesia yang memiliki potensi sumber daya alam yang sangat penting bagi kehidupan masyarakat dan kerugian yang ada ditakutkan akan berdampak besar.

Banjir dan rob yang terjadi menggenangi pemukiman melalui sungai yang ada di kabupaten Pekalongan (Marfai,2013), beberapa sungai tersebut adalah kali Sragi Baru, Mrican, Kali Sengkarang, Kali Bremi, Meduri dan kali Loji. Banjir rob di Kabupaten Pekalongan mengakibatkan dampak negatif, seperti munculnya penyakit dan adanya penambahan luasan serta frekuensi banjir rob yang juga berdampak pada sektor lain. Banjir dan rob perlu ditangani secara terstruktur dan terintegritas dari berbagai pihak, agar diperoleh hasil maksimal.Rob dan banjir di kabupaten Pekalongan dapat diakibatkan oleh beberapa faktor seperti pemanfaatan air tanah secara berlebih, pembabatan hutan bakau, keadaan topografi wilayah, perubahan tata guna lahan, penyempitan bantaran sungai, dan 
sistem drainase yang tidak terawat. (Mayasari,2016)

Dari beberapa faktor tersebut, Kabupaten Pekalongan memiliki topografi yang cukup rendah sehingga berpotensi sebagai wilayah banjir. Beberapa penanganan banjir akibat rob sudah dilakukan oleh Dinas PUSDATARU Provinsi Jawa Tengah diantaranya dengan perbaikan dan pembangunan sarana pengendalian banjir dan pengaman pantai, dilakukan konstruksi perkuatan tebing sungai dan drainase, membatasi aliran masuk rob ke arah daratan, membuat tampungan sementara, memompa air yang tertampung secara periodik. (Afif Salim,2018).Namun demikian, dari berbagai penanganan yang sudah dilaksanakan kurang optimal, sehingga perlu kajian lanjut untuk penanganan banjir yang optimal di Kabupaten Pekalongan.

Tujuan dari penelitian ini adalah untuk mengetahui alternatif penanganan darurat banjir tahun 2021 di Kabupaten Pekalongan, sehingga bagi stakeholder terkait bisa bermanfaat.

\section{Sistem Drainase Eksisting kabupaten Pekalongan}

Sistem drainase eksisting Kabupaten Pekalongan secara garis besar terdiri dari beberapa sungai (Sungai Sragi lama, Sragi baru, Sengkarang, Meduri dan Bremi), permasalahan drainase dan genangan air di Kabupaten pekalongan disebabkan oleh faktor berikut :

1. Secara topografis, Kabupaten Pekalongan berada di dataran rendah,permukaan tanah lebih rendah dari permukaan air laut sehingga wilayah bagian utara air sulit mengalir dan selalu tergenang rob.

2. Wilayah utara kabupaten Pekalongan secara hidrologis merupakan daerah limpahan air hujan dari wilayah Kabupaten Pekalongan, yang merupakan hulu DAS sungai yang mengalir melalui kabupaten Pekalongan.

3. Peningkatan debit banjir akibat perubahan lahan, sebagai konsekuensi dari pengembangan infrastruktur

4. Permasalahan genangan air akibat hujan dan rob wilayah Kabupaten Pekalongan merupakan salah satu permasalahan yang sampai saat ini masih memerlukan penanganan yang serius
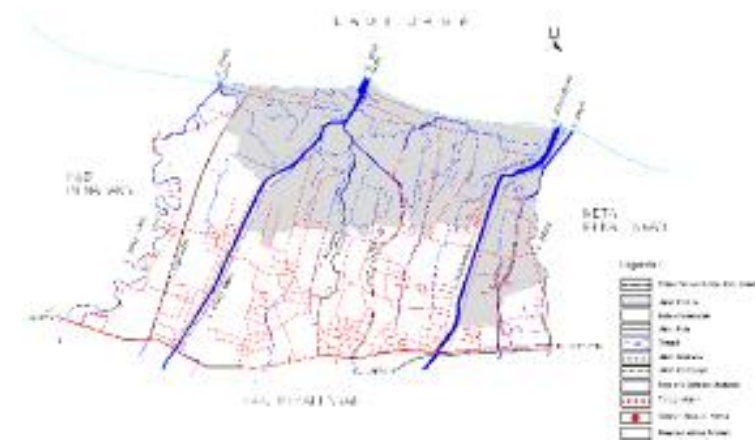

Gambar 1. Peta genangan Rob kabupaten Pekalongan (Seia Konsultan,2019)

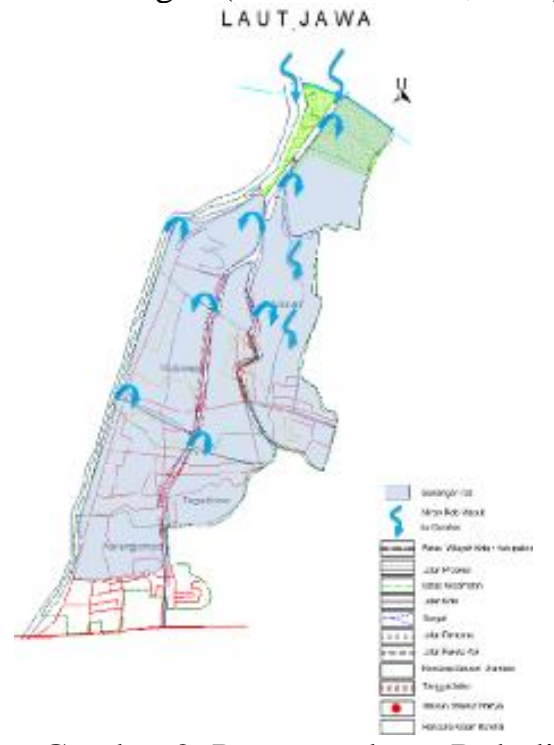

Gambar 2. Peta masuknya Rob di Kabupaten Pekalongan melalui Sungai Meduri, Sengkarang dan Bremi (Studi Teknik Konsultan, 2017)

\section{Pembagian Sub Sistem Drainase Kabupaten Pekalongan}

Pembagian Subsistem Drainase didasarkan pada batas hidrologis masingmasing wilayah. Berdasarkan diliniasi disimpulkan bahwa Subsistem Drainase Kota/ Kabupaten Pekalongan dibagi dalam 17 Subsistem. Pembagian subsistem Drainase seperti pada gambar berikut ini :

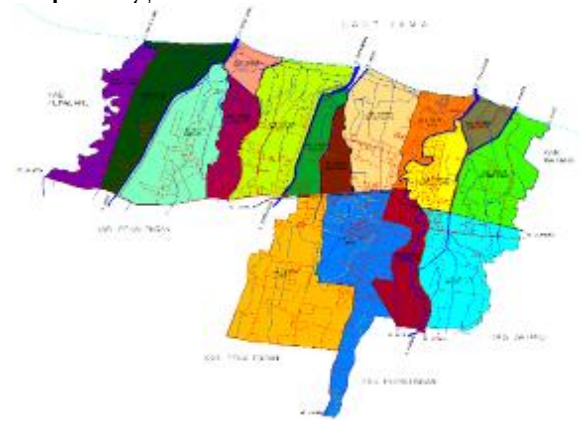

Gambar 3. Sub Sistem Drainase Kabupaten Pekalongan (PT. Indra Karya,2018) 


\section{Sungai Sragi Baru}

Sungai Sragi Baru secara administrasi terletak di Kabupaten Pekalongan dengan Luas Daerah Tangkapan Air (DAS) sebesar 254 $\mathrm{km} 2$ dan panjang sungai mencapai $60 \mathrm{Km}$. Kondisi saat ini sungai Sragi masih cukup bagus.

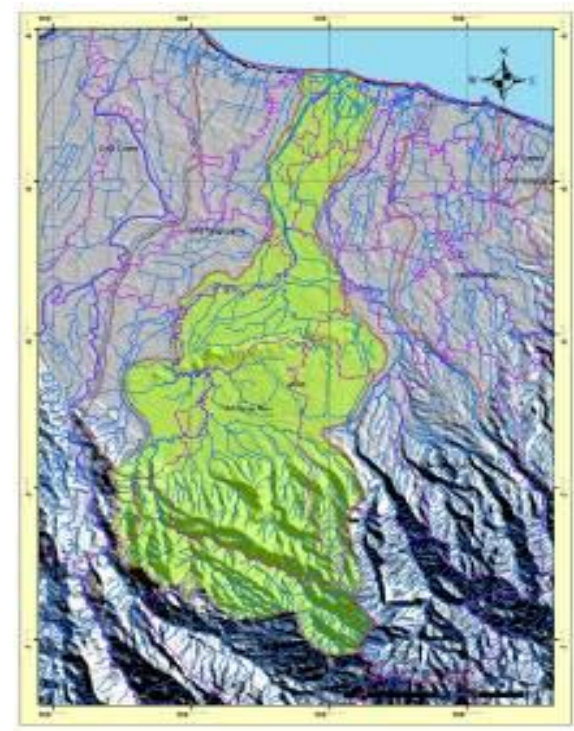

Gambar 4. Peta DAS Sragi Baru

\section{Sungai Bremi}

Sungai Bremi berasal dari saluran pembuang irigasi pada bagian hulu yang masuk dalam wilayah administratif Kabupaten Pekalongan. Alur sungai ini juga melintasi wilayah Kotamadya Pekalongan yang padat. Dibandingkan Sungai Sengkarang dan Sungai Meduri, Sungai Bremi memiliki tingkat pencemaran terberat. Beberapa sistem drainase Kota Pekalongan terhubung langsung dengan Sungai Bremi. Pada bagian hilir sungai ini juga dipenuhi oleh enceng gondok.

DAS Sungai Bremi mempunyai luas $21.58 \mathrm{Km} 2$ dengan panjang sungai $8.61 \mathrm{~km}$. Sub Sistem Drainase Bremi terdiri dari drainase Banyuurip, drainase Boyolangu, drainase Binagriya dan drainase Podosugih.

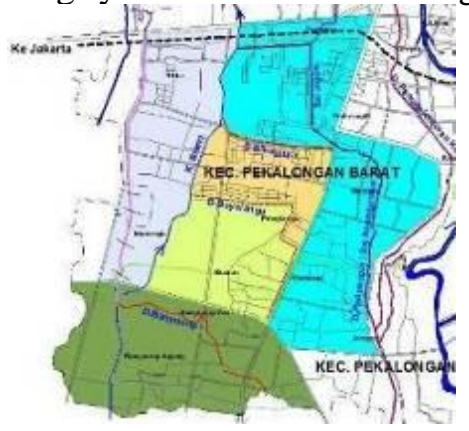

Gambar 5. Skema Sub Sistem Sungai Bremi

\section{Sungai Meduri}

Sungai Meduri berasal dari saluran pembuang irigasi pada bagian hulu yang masuk dalam wilayah adminisratif Kabupaten Pekalongan. Tingkat pencemaran pada ruas Sungai Meduri cukup tinggi. Hal ini disebabkan adanya beberapa pabrik atau industri pada sisi sungai yang langsung membuang limbah ke Sungai Meduri, disamping itu juga akibat pembuangan air kotor penduduk. Pada bagian muara sungai dipenuhi oleh enceng gondok. Sungai Meduri mempunyai luas Daerah Aliran Sungai sebesar $21.13 \mathrm{~km} 2$ dengan panjang sungai sebesar $10.57 \mathrm{Km}$

\section{Dugaan Awal Penyebab Banjir di Kabupaten Pekalongan}

Pada bulan Februari 2021 terjadi hujan dengan intensitas tinggi/ lebat (diatas $50 \mathrm{~mm}$ per hari) hampir sepanjang 7 hari berturutturut, air drainase hujan yang semula mengalir melalui drainase-drainase dan tanggul tidak bisa mengalir langsung ke laut. Berdasar data Unit Hidrografi TNI AL stasiun pengamatan Semarang, tingkat pasang air laut pada bulan Februari 2021 berkisar 0,9-1,1 meter (cukup tinggi).

Akibat dari tingginya intensitas hujan tersebut, banjir terjadi di berbagai daerah sekitar kabupaten Pekalongan, diantaranya di Kecamatan Siwalan dikarenakan diwilayah tersebut terdapat pekerjaan pembentengan tanggul Silempeng yang belum selesai. Selain banjir di Kecamatan Siwalan, banjir terjadi di Kecamatan Wonokerto yang menggenangi beberapa wilayah seperti desa Api-api lor, Sijambe, Bebel, Wonokerto Kulon dan Tratebang, banjir tersebut diakibatkan oleh banyaknya drainase permukaan yang tersumbat, drainase yang tidak dinormalisasi sehingga kapasitas tampungnya tidak optimal,banyaknya pemukiman yang berada pada wilayah cekungan yang elevasinya lebih rendah dari saluran drainase dan tidak optimalnya sistem rumah pompa dan pintu air Mrican. 

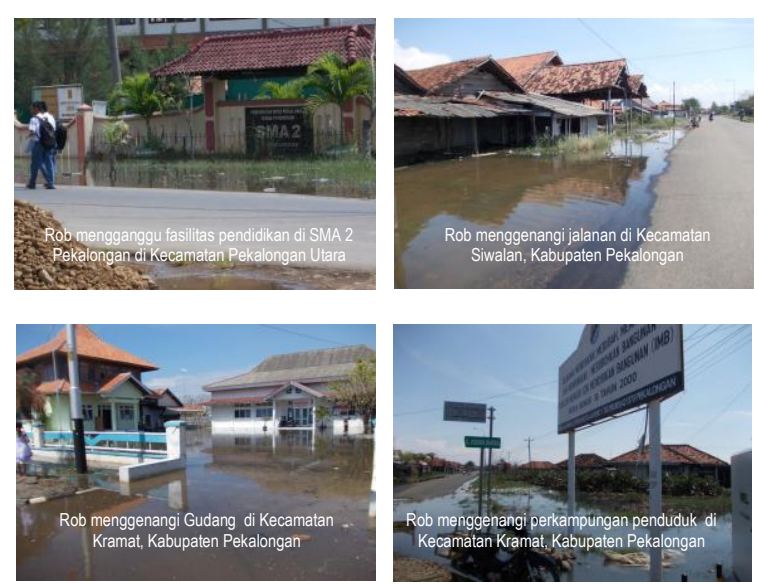

Gambar 6. Kondisi Banjir di Kabupaten Pekalongan 2021

Hal yang sama juga terjadi pada banjir di Kecamatan Tirto yang disebabkan oleh banyaknya drainase yang tersumbat, pintu air sungai Bremi rusak sehingga air rob bisa menuju hulu melewati sungai tersebut, tidak ada pompa yang membuang air kearah laut sehingga terjadi genangan yang sulit untuk surut, daerah pemukiman dengan elevasi rendah di desa Mulyorejo sampai dengan Karangjompo terjadi genangan.

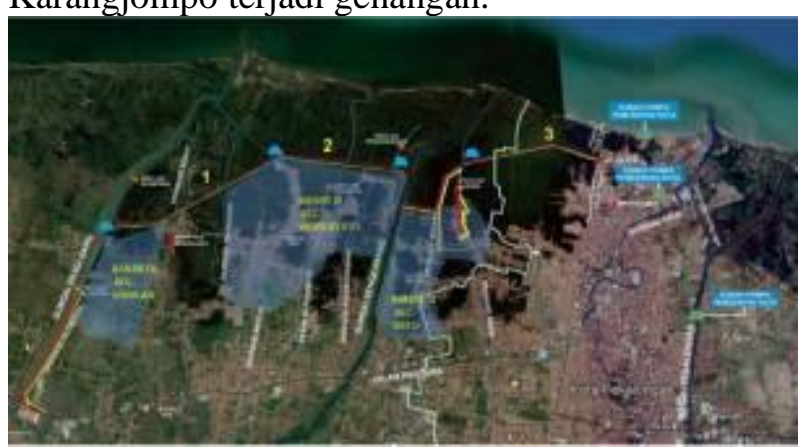

\section{GAMBAR 7. DAERAH GENANGAN BANJIR FEBRUARI $2021 \mathrm{KAB}$ PEKALONGAN}

\section{Permasalahan}

Permasalahan drainase di kabupaten

Pekalongan sangat kompleks yaitu permasalahan alamiah yang meliputi curah hujan, topografi dan geologi dan permasalahan non alamiah yang meliputi aspek yang timbul akibat kegiatan manusia yang berkaitan dengan pemanfaatan dan alih fungsi lahan.

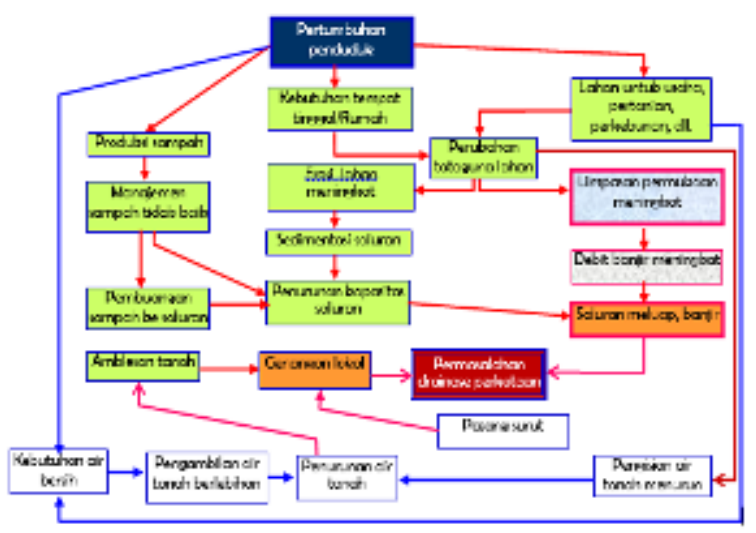

Gambar 8. Permasalahan Banjir di Kabupaten Pekalongan

1. Perubahan tata guna lahan

Perubahan tata guna lahan terjadi sangat cepat seiring dengan pertumbuhan penduduk dan pertumbuhan ekonomi sehingga limpasan permukaan dan laju erosi meningkat khususnya pada tahap pembukaan lahan

\section{Penurunan tanah (land subsidence)}

Penurunan tanah menyebabkan elevasi tanah beberapa wilayah di kabupaten Pekalongan berada dibawah muka air laut, genangan akibat rob selalu terjadi tidak pandang musim hujan atau kemarau.
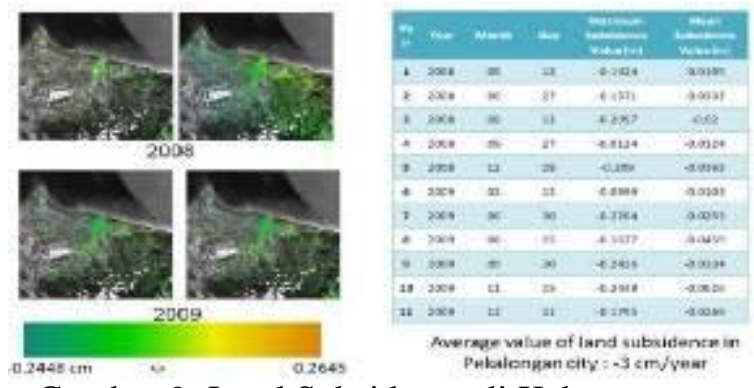

Gambar 9. Land Subsidence di Kabupaten Pekalongan

Penurunan tanah yang terjadi di Kabupaten Pekalongan dikarenakan karena pengambilan air tanah berlebih,pengaruh pengambilan material di kawasan perairan pantai. Berdasarkan kajian dari LAPAN (Lembaga Penerbangan dan Antariksa Nasional) penurunan tanah di Kabupaten pekalongan sebesar $3 \mathrm{~cm} / \mathrm{tahun}$. 
3. Sampah

Pengelolan sampah di Wilayah Kota/ Kabupaten Pekalongan tergolong sangat kurang, masih menggunakan sistem tradisional yaitu sistem timbunan (dumping). Berdasarkan pada dokumen RTRW, kapasitas TPA tidak sebanding dengan produksi sampah Kota/ Kabupaten Pekalongan.

Dampak negatif sampah terhadap sistem drainase diperparah dengan kurangnya kesadaran mayarakat dalam membuang sampah. Masyarakat masih menganggap bahwa sungai/ saluran air merupakan tempat pembuangan sampah. Sampah-sampah yang dibuang sembarangan, berserakan di jalan dan akhirnya disapu air hujan masuk ke sungai/ saluran. Dengan demikian air menjadi kotor, jorok, dan sungai/ saluran menjadi penuh sampah, sehingga pada waktu turun hujan sungai/saluran tersebut akan mampet dan meluber yang mengakibatkan banjir..

\section{Erosi- Sedimentasi}

Erosi pada daerah hulu menyebabkan terjadinya sedimentasi di daerah hilir. Alih fungsi lahan yang tidak terkontrol menimbulkan dampak terhadap kinerja drainase.

Pembukaan/ pengembangan daerah berbukit dengan kemiringan yang terjal dapat mengakibatkan laju erosi yang sangat tinggi jika tidak di ikuti dengan usaha konversi lahan yang tepat. Material erosi yang dibawa aliran air dari hulu, pada saat memasuki sungai/ saluran landai tidak semuanya mampu hanyut ke laut. Sebagian akan diendapkan di sepanjang saluran, sungai, kolam retensi, muara dan badan air yang dilewatinya. Endapan di sungai/ saluran menimbulkan penyempitan dan pendangkalan sehingga kapasitas saluran/ sungai tersebut akan berkurang. Jika sungai/ saluran tersebut meluap, maka lumpur juga akan diendapkan di wilayah yang dilewatinya.

5. Operasi dan pemeliharaan

Operasi dan pemeliharaan untuk proyek sumber daya air di kabupaten Pekalongan khususnya untuk proyek drainase tidak mendapatkan perhatian yang serius oleh pemerintah kabupaten, kesulitan biaya menjadi faktor utama.

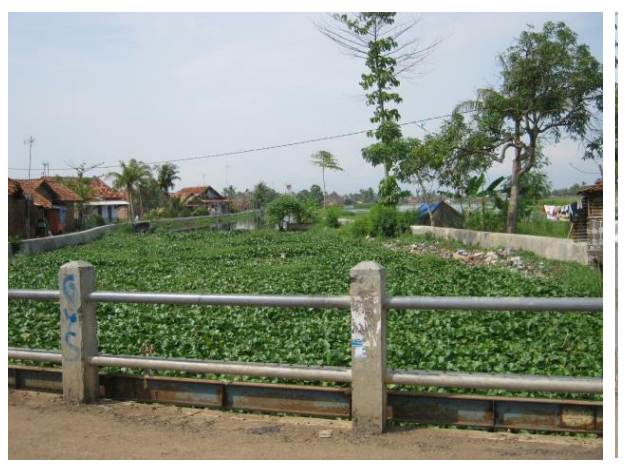

Gambar 10. Gulma menutup saluran akibat kegiatan operasi dan pemeliharaan yang tidak memadai

\section{METODE PENELITIAN}

Penanganan Banjir Kabupaten Pekalongan

Sesuai dengan tujuan dalam tulisan ini, yaitu menemukan alternatif penanganan darurat banjir di Kabupaten Pekalongan yang sesuai kondisi saat ini. Hal ini dilakukan untuk mencapai sasaran dalam penanganan terbaik banjir Kabupaten Pekalongan.

\section{Pengumpulan Data}

Pengumpulan data dilakukan dengan studi kepustakaan dan data sekunder, studi lapangan untuk mendapatkan data primer dan wawancara mendalam dengan stakeholder terkait.

\section{Pengolahan Data}

Hasil studi ini disajikan secara deskriptif kualitatif dengan menggambarkan pemahaman dalam pemilihan alternatif penanganan darurat banjir di Kabupaten Pekalongan.

\section{Pendekatan Studi/ Penelitian}

Dilakukan melalui beberapa ket erkaitan di antaranya mekanisme penelitian, observasi dan penelitian eksperimental.

\section{HASIL DAN PEMBAHASAN}

Dalam menanggulangi banjir yang disebabkan oleh tingginya intensitas hujan dan pasang surut air laut maka direncanakan penanganan sebagai berikut :

\section{Pemodelan Hidrolika HEC RAS Kondisi Eksisting}

Simulasi aliran di hidrolika dilakukan dengan menggunakan software HECRAS 5.03 dengan menggunakan simulasi aliran steady 
flow dan aliran unsteady (UnSteady flow simulation). Data yang digunakan dalam pemodelan Hec RAS adalaha :

1. Data topografi hasil pengukuran topografi sungai sungai yang ditinjau

2. Data debit banjir rencana dari Analisa hidrologi

3. Data fluktuasi muka air pasang surut dari hasil pengamatan pasang surut

4. Data basic desain meliputi trase tanggu

5. Debit banjir rancangan pada masingmasing sungai adalah sebagai berikut

Tabel. Debit Sungai di Kab Pekalongan

\begin{tabular}{|c|c|c|c|}
\hline $\begin{array}{c}\text { TAHU } \\
\text { N }\end{array}$ & $\begin{array}{c}\text { S.BREM } \\
\text { I }\end{array}$ & $\begin{array}{c}\text { S.MEDU } \\
\text { RI }\end{array}$ & $\begin{array}{c}\text { S. SRAGI } \\
\text { BARU }\end{array}$ \\
\hline 5 & 49.24 & 48.17 & 366.01 \\
\hline 10 & 59.00 & 56.81 & 431.63 \\
\hline 25 & 71.91 & 67.73 & 514.55 \\
\hline 50 & 81.93 & 75.82 & 576.06 \\
\hline 100 & 92.30 & 79.90 & 637.12 \\
\hline
\end{tabular}

Skenario Tes Model Hidroulik Sungai

Bremi Meduri dan Sistem Downstream setelah Perencanaan Longstorage dan Tanggul Laut, adalah menggunakan 3 Skenario Simulasi :

1. Pengaliran Debit pada Sistem Inflow menggunakan Debit Rerata Maksimum

2. Pengaliran Kondisi Kali Bremi Banjir Q 5th, Q 10th, Q 25th, Namun Kali Meduri Pengaliran Debit Rerata Maksimum

3. Pengaliran Kondisi Kali Meduri Banjir Q 5th, Q 10th, Q 25th, Namun Kali Bremi Pengaliran Debit Rerata Maksimum.

4. Pemodelan Dilakukan berdasarkan Kondisi Sungai Bremi dan Meduri Mengikuti Kondisi Desain Pada Ruas Bagian Hilir menuju Muara, dan memakai kondisi Eksisting saat ini pada Ruas Hulu sungai dari Jalur Pantura, serta eksisting anak Sungainya

\section{Desain Penanganan Banjir Akibat Rob}

Untuk menanggulangi banjir akibat rob yang terjadi di kabupaten Pekalongan wilayah Sungai Meduri maka direncanakan pintu air yang diletakkan di hilir sungai Meduri dengan tujuan untuk membatasi jangkauan pasang air laut pintu Meduri direncanakan 8 buah pintu dengan lebar masing-masing 1,50 meter, sedangkan di sungai Bremi dengan perbaikan pintu Bremi eksisting yang kondisinya sudah rusak.

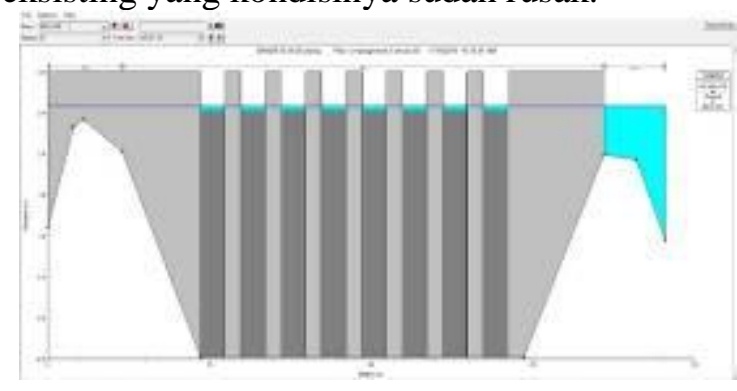

Gambar 11. Rencana pintu Meduri pada HEC RAS

\section{Desain Penanganan Terhadap Banjir Kedepan}

Alternatif penanganan banjir di kabupaten Pekalongan adalah sebagai berikut:

1. Normalisasi sungai dan pembuatan tanggul/parapet. Tanggul dimulai dari jembatan pantura ke selatan (hulu).

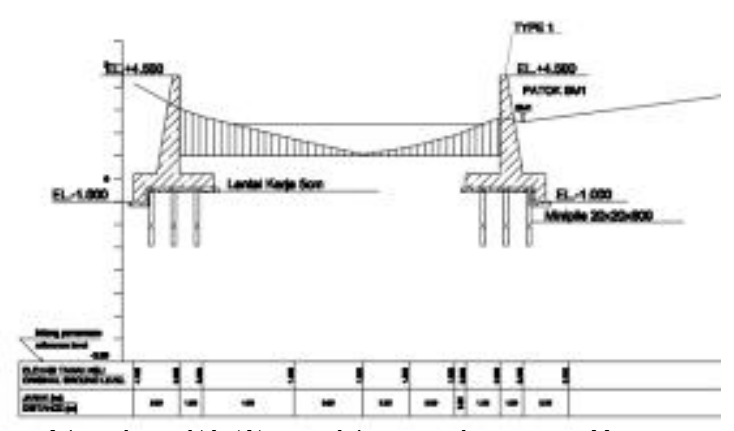

Gambar 1 2 . I 1pical tanggul sunga1 Bremı

2. Normalisasi dengan pengaturan kedalaman Saluran (Dregging) dan penambahan Tanggul menggunakan Parapet /Sheetpile dan atau urugan tanah pada Sungai Meduri.

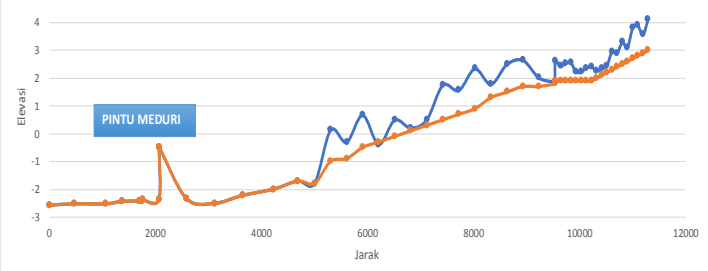

Gambar 13. Konsep Desain Normalisasi Sungai Meduri

\section{Penanganan Banjir yang Sudah Berjalan}

Berikut beberapa penanganan banjir di yang sudah dialksanakan pada 2020 di kabupaten Pekalongan :

1. Penambahan Pintu Sorong Darurat 
Lokasi penambahan pintu sorong darurat sudah dilakukan di drainase Semut hilir, drainase Tratebang hilir, drainase Pekuncen hilir dan drainase Pesanggrahan dengan konstruksi Pintu air Frame baja galvanis, daun pintu Fiberglass, saluran beton Box Culvert Pra cetak.

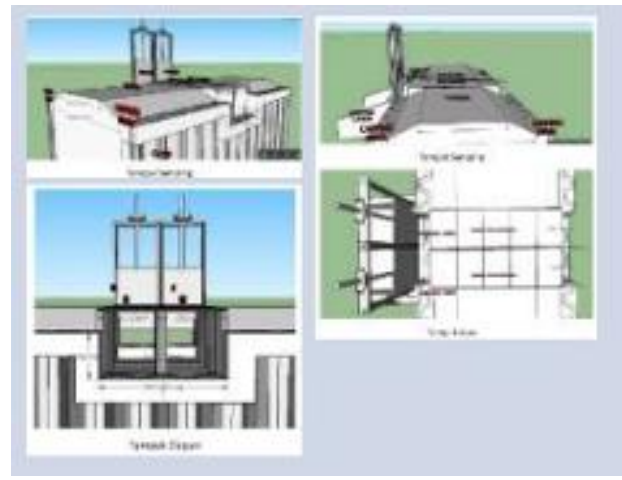

Gambar 14. Disain pintu sorong darurat

Cara penanganan : pintu air didesain untuk 2 pintu untuk menanggulangi ketika level air tinggi pada Long Storage Silempeng-Sengkarang.

2. Pengadaan Pompa Air Mobile

Rencana pengadaan Pompa air mobile secara darurat bisa dimobilisasi ke lokasi yang membutuhkan ketika terjadi banjir akibat rob atau intensitas hujan tinggi. Rencana pengadaan sebanyak 2 unit dengan kapasitas 250 liter/ detik. Penanganan ini butuh rekasi cepat tanggap.

3. Tanggul dengan CCSP (Corrugated Concrete Sheet Pile)

Tanggul dengan CCSP beton pra cetak yang dipancang dengan perkuatan pile cap beton bertulang. Penanganan dengan CCSP sudah dilakukan di Sungai Meduri. Spesifikasi CCSP yang digunakan adalah CCSP W 500-1000 dengan mutu beton K700 dan panjang 12 meter.

4. Rehabilitasi pintu air Sungai Bremi

Rehabilitasi pada Sungai Bremi yang sudah dilakukan adalah dengan mengembalikan fungsi pintu air Sungai Bremi, perbaikan daun pintu dan mekanisme penggeraknya, menyiapkan lokasi pompa air mobile dengan bekerjasama stakeholder terkait (Pemkab Pekalongan). Penanganan tersebut berhasil menutup Sungai Bremi dari pengaruh banjir akibat rob.

5. Pembangunan Rumah Pompa Mrican
Pembangunan rumah pompa Mrican merupakan penanganan banjir yang sudah dialkukan di Sungai Mrican, kapasitas pompa yang ada $3 \times 2 \mathrm{~m} 3 /$ detik dengan dilengkapi generator set dan alat kontrolnya. Penanganan ini dianggap kurang efektif karena kapasitas pompa terlalu kecil, sehingga perlu ditingkatkan menjadi $8 \times 2 \mathrm{~m} 3 /$ detik.

6. Pembangunan tanggul tanah Silempeng dan Rehabilitasi Pintu air Boyoteluk

Penanganan ini sudah dilakukan dengan meninggikan tanggul drainase Silempeng sepanjang 2.200 meter.

\section{Penanganan Darurat Banjir}

Berikut beberapa penanganan darurat yang dilakukan selama banjir Februari 2021 Kabupaten Pekalongan :

1. Pembukaan saluran darurat pembuang dari Long Storage Silempeng- Sengkarang

Lokasi penambahan pintu sorong darurat sudah dilakukan di drainase Semut hilir, drainase Tratebang hilir. Cara penanganan yang dilakukan adalah dengan membuka buangan di Tratebang hilir dengan lebar bukaan 2 meter, dalam bukaan 1 meter dan beda elevasi aliran 40 $\mathrm{cm}$, sedangkan untuk drainase pada buangan di Mrican hilir lebar bukaan 4 meter, dalam bukaan 1 meter dengan beda elevasi aliran $40 \mathrm{~cm}$.

2. Penyiapan sand bag dan karung-karung besar untuk penanganan darurat yang bisa dimanfaatkan untuk penanganan banjir dengan membuat tanggul darurat

\section{PENUTUP}

Bencana banjir yang terjadi di Kabupaten Pekalongan yang disebabkan oleh intensitas hujan tinggi dan pasang surut air laut akibat rob menimbulkan beberapa kerugian bagi kondisi masyarakat sekitar,dari kerugian material, bangunan yang rusak, lingkungan yang kotor, hingga lumpuhnya lalulintas di sekitar lokasi. Penyebab banjir kabupaten Pekalongan pada Februari 2021 dipicu tingginya intensitas hujan yang tinggi dan pasang air laut yang mencapai 0,8 -1,1 meter. Akibatnya banjir menggenangi sebagian besar daerah pesisir kabupaten Pekalongan. Penanganan banjir yang sudah dilakukan adalah dengan menambah pintu sorong darurat pada drainase, pengadaan pompa air mobile 
kapasitas 250 liter/detik, tanggul CCSP (Corugated Concrete Sheet Pile), rehabilitasi pintu air Sungai Bremi, pembangunan rumah pompa Mrican kapasitas $8 \times 2 \mathrm{~m} 3 /$ detik, dan pembangunan tanggul tanah Silempeng sepanjang 2.200 meter. Adapun penanganan darurat yang dilakukan ketika banjir Februari 2021 adalah dengan pembukaan Long Storage Silempeng- Sengkarang dan penyiapan sandbag serta karung-karung besar untuk penanganan darurat.

\section{DAFTAR PUSTAKA}

Afif Salim. (2018). Penanganan Banjir dan Rob Wilayah Pekalongan. Jurnal Teknik Sipil Untag Semarang

Agus B Siswanto,dkk. 2019. Manajemen Proyek. Yogyakarta : Pilar Nusantara.

Hermawan, A. (2011). Pemetaan Banjir Rob dan Penilaian Potensi Kerugian Lahan Pertanian Padi Sawah akibat banjir rob wilayah pesisir kecamatan Wedung. Yogyakarta: Fakultas Geografi UGM

Kodoatie. Robert.J.(2013). Rekayasa dan Manajemen Banjir Kota. Yogyakarta: ANDI Yogyakarta

Marfai,MA.(2013).Bencana Banjir Rob, Studi Pendahuluan Banjir Pesisir Jakarta. Yogyakarta : Graha Ilmu

Maulana, S. (2012). Pemodelan Spasial untuk Prediksi Luas Genangan Banjir Pasang Laut Wilayah Pesisir Kota Jakarta. Yogyakarta : Fakultas Geografi UGM

Maya Sari. (2016). Banjir Rob Pengertian, Karakteristik, Dampak dan Cara Mengatasinya.http://ilmugeografi.com/ (di unduh 8 Maret 2021)

Triatmodjo, B. (1999). Teknik Pantai. Yogyakarta: UGM Press 